\title{
Etika Kebijakan Publik Pada Program Keluarga Harapan di Kota Palopo
}

\author{
${ }^{1}$ Didik Iskandar \\ ${ }^{1}$ Universitas STISIP Veteran Palopo, Indonesia; didik.iskandar27@gmail.com
}

\begin{abstract}
Ethics is one approach that is often used in public policy in the framework of public administration. The Family Hope Program is an empowerment program for underprivileged communities by providing conditional cash assistance. This study will to describe the benefits, great benefits, and benefits for as many people as possible in terms of the ethical perspective of utilitarianism from a policy in the form of a program, namely, implementation of the family of hope program in Palopo City. The object of this research is was family hope program at Palopo City. This study uses an evaluation method through a qualitative approach. Data obtained through data presentation, data reduction, verification and conclusion drawing. The results of the study indicate that the benefits obtained to implementation of family hope program in Palopo City are based on utilitarian ethics, namely there are additional costs in meeting education and health needs. Furthermore, great benefit that can be obtained to program recipients is a change in mindset to prioritize and care more about the importance of children's education and in the health sector, namely the importance of regular check-ups to the posyandu for pregnant women and toddlers. The great benefit for as many people as possible that will be found in implementation on this program is that there is an insurance effect for program recipients, namely future security guarantees for $\mathrm{PKH}$ participants as a means of motivation to see education and health as potential welfare.
\end{abstract}

Keywords: Local Government, ethics, public policy, program keluarga harapan (PKH).

\section{Pendahuluan}

Kebijakan publik merupakan bagian dari beberapa dimensi strategis yang menjadi fokus bahasan dalam studi administrasi publik. Pentingnya pembahasan konsep, teori dan aplikasi mengenai kebijakan publik seringkali menjadi tujuan utama dari serangkaian aktifitas ilmiah dalam administrasi publik. Salah satu pendekatan yang sering digunakan dalam perumusan kebijakan publik dalam kerangka administrasi publik ialah pendekatan etika. Pada hakikatnya dalam administrasi publik, dimensi etika tidak hanya berkaitan tentang benar atau salah namun lebih mengrah kepada hal yang berkitan dengan baik atau buruknya suatu tindakan.

Dua fungsi yang berbeda yaitu fungsi administrasi dan fungsi politik yang merupakan fungsi pada dikotomi paradigma antara administrasi dan politik. Disisi fungsi politik berhubungan dengan pembuatan atau perumusan kebijakan sedangkan pada Fungsi administrasi berkaitan tentang pelaksanaan kebijakan yang telah dirumuskan atau ditetapkan. Ini meberikan isyarat bahwa kedudukan kekuasaan politik merupakan ranah untuk pembuatan kebijakan dan disisi yang lain kekuasaan dari administrasi publik berada pada ranah pelaksanaan atau pengimplementasian kebijakan-kebijakan tersebut. Tentu fenomena tentang adanya dikotonomi antara administrasi dan politik menjadikan posisi administrasi publik berada pada kondisi yang dilmeatis (Kumorotomo, 2008).

Kebijakan publik merupakan apapun yang menjadi pilihan oleh pemerintah untuk ditempuh maupun tidak dilakukan termasuk mengatur konflik dalam masyarakat; mengorganisir masyarakat untuk melakukan konflik dengan masyarakat lain; mendistribusikan berbagai macam penghargaan simbolis dan layanan material kepada anggota masyarakat; dan juga memungut pajak dari masyarakat. Sehingga dengan begitu, kebijakan publik diartikan sebagai sebuah aksi yang dapat mengatur perilaku, mengatur birokrasi, mendistribusikan manfaat, atau mengekstraksi pajak (Dye, 2013). Selain itu kebijakan publik terkadang di definisikan sebagai wujud tekanan pemerintah yang bersifat kontinum atau berkelanjutan yang 
diorientasikan kepada kepentingan kelompok yang kurang berdaya agar mampu hidup dan ikut terlibat dalam urusan publik. Hal tersebut memberikan gambaran bahwa tidak selalu kebijakan melihat sebagai pemanfaatan strategis dari sumber daya namun kadang juga melihat dimensi moral yang sangat mendalam bahkan sangat menentukan (Donahue, 2003).

Birkland (2020) memberikan penjelasan bahwa tidak ada definisi tunggal yang dapat dikembangkan, tetapi, setidaknya kita dapat melihat atribut kunci dari kebijakan publik itu sendiri, diantranya: Pertama, Kebijakan publik dibuat sebagai tanggapan atas beberapa jenis masalah yang dianggap layak untuk mendapat tanggapan pemerintah; kedua, kebijakan publik dibuat untuk "kepentingan umum", sebuah istilah yang diapit tanda kutip karena tidak semua orang akan setuju dengan kepentingan publik; ketiga, kebijakan diinterpretasikan dan diimplementasikan oleh aktor publik dan swasta yang memiliki motivasi berbeda, sehingga akan membawa interpretasi yang berbeda terhadap masalah dan solusi yang ditawarkan; keempat, kebijakan publik berorientasi pada tujuan atau keadaan yang diinginkan, seperti mengurangi insiden atau keparahan dari beberapa jenis masalah; kelima, kebijakan pada akhirnya dibuat oleh pemerintah yang bahkan jika ide tersebut datang dari luar pemerintah atau melalui interaksi aktor pemerintah dan non-pemerintah.

Meskipun mungkin ada ketidak sepakatan dengan prinsip yang benar dalam situasi, kita mengharapkan pengambilan keputusan yang berprinsip, dalam arti konsistensi, koherensi, dan tanpa kesewenang-wenangan (Frederickson, 1997). Dalam administrasi publik etika dianalogikan sebagai dimensi sensor untuk menilai baik buruknya sebuah tindakan yang juga memberikan pengaruh pada pencapaian tujuan-tujuan administrasi publik dan juga organisasi publik (Keban, 2008). Lever dan Poama (2019) mengungkapkan bahwa terdapat perbdebatan yang sangat alot tentang apakah etika pantas atau tidak pantas untuk dilibatkan dalam kebijakan publik. Etika kebijakan publik dalam masyarakat demokratis melibatkan setidaknya dua kendala penting yang mungkin menjadi kendala dalam masyarakat. Pertama, dalam desain dan implementasinya, kebijakan publik harus mencerminkan "penghormatan dan kepedulian yang sama" terhadap kesejahteraan dan hak warga negara. Kedua, kebijakan tersebut juga harus melindungi dan mendorong kapasitas masyarakat untuk berbagi dalam proses pemerintahan dan juga tentang bagaimanapun proses itu dipahami. Oleh karena itu, pemerintahan demokratis datang dalam berbagai bentuk, yang mencerminkan cita-cita, keadaan, dan kebutuhan politik yang berbeda, sehingga perbedaan antara pemerintahan yang demokratis dan tidak demokratis memberikan lensa yang bermanfaat untuk membayangkan etika kebijakan public.

Pemahaman administrator terhadap nilai dan orientasi keputusan mampu memberikan kontribusi terhadap perilaku penentu etis/tidak etis dalam pengambilan keputusan. Namun, administrator juga sering mencari bimbingan atau kerangka kerja untuk menentukan apa saja tindakan yang "etis yang tepat". Dihadapkan dengan ketidakpastian dalam situasi etis, pencarian administrator untuk solusi etis haruslah yang benar dan bertanggung jawab. Satu menganggap program alternatifaksi. Nilai-nilai apa yang menjadi prioritas tertinggi? Kepentingan siapa layak menjadi pertimbangan terbesar? Apa etis benar? Teori normatif atau preskriptif menawarkan bimbingan untuk yang sebaiknya dilakukan dan tindakan etis apa saja yang benar (Wolf, 2020).

Selain itu, orientasi terhadap konsekuensi-konsekuensi yang memberikan manfaat atas suatu kebijakan yang ditempuh juga banyak dikemukakan dalam pandangan etika utilitarianisme. Dengan mengusung tema the great happines for the great numbers, John Stuart Mill (1864) dalam pandangan utilitarianisme menegaskan bahwa segala keputusan atau kebijakan akan dianggap etis ketika mampu memberikan manfaat, manfaat yang besar, dan manfaat yang luas bagi sebanyak mungkin orang (Parsons, 2014). Wujud keputusan pemerintah dalam mewujudkan proses pembangunan pad berbagai sektor ditempuh melalui kebijakan dengan tujuan untuk pencapaian kesejahteraan yang lebih baik. Agar mampu menjamin 
pemerataan resources atau sumber daya pemerintah harus menempuh kebijakan yang lebih inklusif yang juga berpihak pada kelompok-kelompok yang kurang beruntung seperti masyarakat prasejahtera (Haryatmoko, 2013).

Dalam konteks hadirnya program keluarga harapan sebagai produk kebijakan pemerintah, masyarakat memiliki respon positif terhadap PKH itu sendiri yang tercermin dari tingkat pemahaman masyarakat prasejahtera mengenai tujuan dan manfaat program keluarga harapan. Jika diamati dari kondisi penerima program keluarga harapan tersebut terdapat kesadaran untuk mereka gunakan sebagai alternatif menyelsaikan masalah sosial masyarakat prasejahtera dalam hal pendidikan dan kesehatan. Oleh karena efek yang mampu mempengaruhi sendi-sendi kehidupan sosial ekonomi masyarakat serta respon positif yang diterima oleh program ini maka penting kiranya dalam proses kebijakannya memperhatkan nilai-nilai etis perumusan kebijakan publik. Namun pelaksanannya PKH masih dianggap kurang memberi dampak atau manfaat yang secara luas dapat dirasakan oleh masyarakat prasejahtera. Terkhusus apakah dengan program ini mampu memebrikan manfaat yang cukup besar pada situasi yang lebih besar yaitu tidak hanya terbatas pada peningkatan pendapatan untuk pemenhunan kebutuhan disektor kesehatan maupun pendidikan tetapi juga memberikan efek edukatif yang mampu dirasakan manfaatnya secara luas dan berkelanjutan.

PKH merupakan program bantuan dan perlindungan sosial yang termasuk dalam klaster I strategi penanggulangan kemiskinan di Indonesia yang berkaitan dengan pendidikan, kesehatan dan pemenuhan dasar bagi lansia dan penyandang disabilitas berat. Program Keluarga Harapan (PKH) adalah program pemberian bantuan tunai bersyarat kepada keluarga sangat miskin (KSM) yang memenuhi syarat kepesertaan dan ditetapkan oleh kementrian sosial. Melalui PKH, RTSM diarahkan agar mempunyai akses pelayanan sosial dasar seperti layanan kesehatan, layanan di bidang pendidikan, dan termasuk akses keberbagai program perlindungan sosial yang juga merupakan program terpadu secara berkesinambungan. $\mathrm{PKH}$ diorientasikan untuk menjadi pusat dan starting point dalam penanggulangan kemiskinan yang melibatkan berbagai program penanggulangan dan pemberdayaan sosial nasional. Berdasarakan dat Badan pusat statistic PKH cukup berhasil menurunkan angka kemiskinan dan meningkatkan taraf hidup masyarkat sejahtera yang pada Maret tahun 2016 masih sebesar $10,86 \%$ dari total penduduk atau dapat dikatakan menjadi 28,01 juta jiwa (BPS, 2016).

Berdasarkan dengan ketetapan yang tertuang dalam RPJMN tahun 2015 sampai dengan 2019 pemerintah sampai saat ini telah melakukan penanggulangan kemiskinan kekisaran antara 7 sampai 8\% RTSM. PKH didukung oleh pendamping dengan pendidikan relatif tinggi dan berlatar belakang disiplin ilmu yan mendukung untuk perubahan sikap dan prilaku, selain itu pengembangan karier sebagai seorang pendamping PKH hanya berupa prestasi kerja, maka dari itu kinerja pendamping PKH lebih unggul dibanding kelemahannya dengan sistem kontrak, keterampilan penunjang dan konsekuensi jarak tempuh ketempat kerja. Program Keluarga Harapan seara signifikan memberikan dampak terhadap pola konsumsi rumah tangga menjadi lebih terarah dan lebih baik, dan juga mampu menambah jumlah konsumsi rumah tangga kelompok penerima manfaat sebesar 4,8\% di Indonesia (Kemensos, 2020).

Studi ini mengangkat tentang pelaksanaan program keluarga harapan yang ditujukan ke masyarakat prasejahtera di Kota Palopo sebagai bagian dari strategi pemberantasan kemiskinan berbasis perlindungan dan jaminan sosial dimana dalam banyak kasus tentang bantuan sosial kepada rakyat miskin kerap kali mengalami penyimpangan dalam pelaksanaannya. Terlebih lagi melihat maraknya program sejenis yang dilaksanakan tanpa memperhatikan nilai guna jangka panjang.Pentingnya melibatkan dimensi etika dalam hal tahapan-tahapan perumusan kebijakan publik merupakan landasan awal terkait dengan banyaknya temuan yang menjadi kendala pokok dalam pemberlakuan bantuan program keluarga harapan di kota palopo seperti, rendahnya nilai yang diberikan dalam bantuan tersebut serta kurang efektifnya pemerintah 
dalam menentukan kelompok keluarga miskin yang berhak mendapatkan bantuan. Penelitian ini bertujuan untuk mendeskripsikan manfaat, manfaat yang besar, serta manfaat bagi sebanyak mungkin orang ditinjau dari perspektif etika utilitarianisme dari suatu kebijakan dalam bentuk program yakni pelaksanaan program keluarga harapan di Kota Palopo.

\section{Metode Penelitian}

Pada kesempatan ini penelitian bersifat kualitatif dengan menggunakan metode evaluasi. Evaluasi program dimaksudkan agar mampu menilai apakah program disusun, dijalankan, dan bermanfaat bagi kelompok-kelompok yang terlibat dalam program. Sehingga pada hakikatnya evaluasi program bertujuan untuk mengidentifikasi informasi sebanyak mungkin guna menghasilkan gambaran pencanangan dan pemberlakuan program. (Patton, 2009)

Kota Palopo menjadi lokasi utama penelitian ini. Objek penelitian ialah yang terkait pelaksanaan program keluarga harapan ini yakni diantaranya: Dinas Sosial, tenaga pendamping program, Kelompok penerima manfaat program di Kota Palopo, Pemerintah Kota Palopo, Tim Pendamping Pelaksanaan Program Keluarga Harapan di Tingkat Kota, Dan KPM yang menerima manfaat program ini.

Jenis data dikumpulkan yaitu data primer yang merupakan data melalui sumber-sumber tidak tertulis atau data lapangan melalui metode wawancara mendalam (indepthinterview) terhadap informan dan juga data sekunder yang diperoleh melalui dokumen yang diperlukan. Diantaranya: data hasil pelaksanaan program keluarga harapan di kota palopo yang dalam hal ini bisa diperoleh dari Dinas Sosial, pendamping program PKH dan Kelompok penerima manfaat program PKH di Kota Palopo

Analisis data ditempuh dengan beberapa langkah dengan mengacu kepada arahan Creswell (2014), yang meliputi aktivitas: Triangulasi data, Member checking, Melakukan pengamatan berulang di lokasi penelitian dalam waktu yang tidak begitu lama sampai mendapatkan jawaban sama dari berbagai informan, dan menerapkan pola partisipatoris, informan kunci, dan informan lainnya melalui diskusi untuk memperoleh komentar terhadap temuan.

\section{Hasil dan Pembahasan}

Dalam Proses penetapan sasaran di alokasikan kepada Kelompok Penerima Manfaat (KPM) dimana dalam satu KPM termuat satu atau lebih komponen yang merupakan syarat untuk menerima bantuan dari PKH. Komponen yang dimaksudkan adalah KPM tersebut memilki anak sekolah di jenjang SD, jenjang SMP, dan SMA ibu serta yang memilik balita dan ibu hamil. Di kota Palopo pelaksanaan Program ini sudah dilaksanakan mulai tahun 2013 sampai dengan saat ini dengan tingkat jumlah penerima bantuannya yang fluktuatif tiap tahunnya seperti yang terdapat dalam tabel di bawah ini:

\section{Tabel 1}

\section{Data Penerima Manfaat PKH di Kota Palopo Dari Tahun 2013 s/d Agustus Tahun 2019}

\begin{tabular}{clccccccc}
\hline \multirow{2}{*}{ NO } & $\begin{array}{c}\text { NAMA } \\
\text { KECAMATAN }\end{array}$ & $\mathbf{2 0 1 3}$ & $\mathbf{2 0 1 4}$ & $\mathbf{2 0 1 5}$ & $\mathbf{2 0 1 6}$ & $\mathbf{2 0 1 7}$ & $\mathbf{2 0 1 8}$ & $\mathbf{2 0 1 9}$ \\
\hline 1 & BARA & 209 & 207 & 207 & 409 & 397 & 496 & 475 \\
\hline 2 & TELLUWANUA & 306 & 299 & 291 & 680 & 666 & 809 & 804 \\
\hline 3 & WARA & 146 & 141 & 138 & 266 & 247 & 321 & 310 \\
\hline 4 & WARA TIMUR & 216 & 204 & 196 & 580 & 557 & 583 & 556 \\
\hline
\end{tabular}




\begin{tabular}{|c|c|c|c|c|c|c|c|c|}
\hline 5 & WARA SELATAN & 0 & 91 & 92 & 222 & 213 & 225 & 219 \\
\hline 6 & WARA UTARA & 0 & 123 & 124 & 245 & 230 & 274 & 266 \\
\hline 7 & MUNGKAJANG & 0 & 0 & 126 & 223 & 217 & 224 & 222 \\
\hline 8 & SENDANA & 0 & 0 & 163 & 321 & 309 & 359 & 351 \\
\hline 9 & WARA BARAT & 0 & 0 & 176 & 298 & 286 & 331 & 316 \\
\hline \multicolumn{2}{|r|}{ TOTAL JUMLAH } & 877 & 1065 & 1513 & 3244 & 3122 & 3622 & 3519 \\
\hline
\end{tabular}

Jumlah bantuan dana yang diterima oleh tiap KPM bervariatif yang diasumsikan berdasarkan jumlah komponen yang terdapat dalam satu KPM dimana terdapat bantuan tetap sebanyak Rp. 300.000,-/bulan dengan bantuan minimum yang diterima sebesar Rp. 800.000,/bulan jika satu KSM cuman memiliki salah satu dari komponen serta jumlah maksimum Rp. 2.800.000,-/bulan jika KPM tersebut memiliki semua komponen dalam persyaratan pemberian bantuan oleh program ini.

Manfaat yang langsung yang dapat dirasakan oleh penerima bantuan dari PKH ini adalah memberikan pendapatan tambahan dalam hal membiayai kebutuhan pendidikan anak-anak mereka. Bantuan berupa bentuk uang tunai yang diberikan program ini juga diarasakan manfaat langsungnya di bidang kesehatan seperti yang dirasakan oleh salah satu penerima bantuan yang dimana ia memiliki komponen anak balita yang rutin untuk diperiksa kesehatannya di psoyandu terdekat. Selain itu ibu hamil yang juga menjadi komponen penerima manfaat dari bantuan program ini turut meraskan dampaknya yang nyata. Penyaluran bantuan yang diterima langsung oleh masyarakat sebagai objek pelaksanaan program ini sangat dirasakan dampak langsungnya karena tanpa melalui proses yang berbelit serta tanpa ada potongan satu rupiah pun baik dari pihak penyelenggara di tingkat pusat, di tingkat kota, di tingkat kecamatan smaupun di Kantor Pos Kota Palopo sebagai lembaga yang di percayakan untuk menyalurkan bantuan ini langsung ke tangan penerima bantuan dalam hal ini KPM Kota Palopo.

\section{Manfaat Dalam Situasi Yang Lebih Besar}

Hasil penelitian di lapangan menemukan banyaknya manfaat yang diterima bagi penerima bantuan dalam hal ini KSM yang menjadi sasaran program. Kondisi ini tidak terlepas dari peran aktif pendamping program sebagai aktor yang mengatur dan mengarahkan para penerima dalam pemanfaatan dana bantuan yang diberikan. Selain itu, pendamping juga berfungsi evaluator dalam menilai seberapa komitmen peserta PKH dalam menjalankan kewajibannya. Pengontrolan yang dilakukan pendamping dilakukan bagi peserta $\mathrm{PKH}$ dalam pemeriksaan bayi dan balita ke posyandu serta seberapa aktif anak-anak peserta PKH dalam bersekolah. Dalam pengamatana di posyandu misalnya, pendamping sangat intens mengawasi peserta $\mathrm{PKH}$ untuk melakukan posyandu rutin yang diadakan tiap bulannya dan juga berkoordinasi ke pihak pegawai posyandu tentang hal-hal yang merupakan kewajiban dari peserta yang harus dilaksanakan. Untuk pengamatan di sekolah pendamping melakukan cek kehadiran anak didik dari peserta $\mathrm{PKH}$ yang juga berkoordinasi dengan pihak sekolah seperti guru dan kepala sekolah.

Dengan dilakukannya pengawasan yang terus menerus maka pihak penyelenggara mengharapakan terjadi kesadaran bagi peserta PKH tentang pentingnya pemeriksaan kesehatan yang rutin dan juga pentingnya mendidik anak mereka agar rajin bersekolah. Dari data yang diperoleh di lapangan memperlihatkan hasil yang baik dalam kaitannya memberikan kesadaran bagi peserta untuk lebih peduli terhadap kesehatan mereka. Hal ini dibuktikan dari meningkatnya tingkat partisipasi peserta program dalam melakukan kegiatan rutin di posyandu juga meningkatnya angka kehadiran anak peserta PKH disekolah. Selain pengawasan yang melekat yang dilakukan oleh pendamping, manfaat yang sangat terasa yang dirasakan oleh peserta program ialah bentuk bantuan tunai dari program ini sifatnya rutin dan berkesinambungan. Dibanding dengan program lain, para penerima menganggap bentuk bantuan yang rutin ini sebagai motivasi bagi mereka karena dengan pola yang teratur dalam pemeberian bantuan 
membuat perubahan pola perilaku terhadap kepedulian dalam hal kesehatan dan pendidikan. Berdasarkan kondisi objektif yang ada memperlihatkan bahwa dengan intensnya para pendamping program melakukan evaluasi dan mengarahkan peserta juga dengan bentuk bantuan yang diterima ditiap triwulannya secara tidak langsung memberikan dampak yang sangat positif seperti terjadi perubahan pola pikir masyarakat tentang pentingnya kesehatan dan pendidikan dalam memperbaiki tatanan kehidupan mereka.

\section{Manfaat Yang Besar Bagi Sebanyak Mungkin Orang}

Program Keluarga Harapan sebagai bentuk kebijakan pemerintah dalam mensiasati pengurangan angka kemiskinan dianggap sebagian pihak sebagai salah satu ide yang cukup briliant. Hal itu disebabkan bahwa program ini mempunyai visi yang besar kedepannya kaitannya dalam memutus mata rantai kemiskinan dimana sasaran utama dalam program ini ialah menciptakan generasi yang berkualitas. Bantuan yang tidak hanya memfokuskan pada bidang kesehatan dan pendidikan bagi anak sekolah dan balita ini juga terkonsentrasi pada janin ibu hamil yang dianggap sebagai aset untuk menciptakan kondisi yang lebih baik pada satu KSM. fokus pada anak sekolah, anak balita dan bayi merupakan inti dari dari program ini dimana kedepannya nanti diharapakan anak-anak yang mendapatkan bantuan nantinya akan memiliki kualitas diri yang jauh lebih baik dari saat ini. Seperti mendapatkan pendidikan yang baik untuk menunjang mereka mendapatkan pekerjaan yang jauh lebih baik dari orangtua mereka sebelumnya. Sehingga anak yang telah mendapatkan kualitas diri yang baik dapat membawa keluarga mereka ikut serta menjauh dari rantai kemiskinan. Berdasarkan realitas seperti itulah maka sebagaian pihak mengganggap bahwa PKH ini memberikan efek yang baik kedepannya sebagai bentuk jaminan sosial, pendidikan dan kesehatan bagi penerimanya.

\section{Simpulan}

Penelitian ini menunjukkan bahwa pada dasarnya PKH sangat bermanfaat bagi masyarakat prasejahtera yang mayoritas tidak memiliki penghasilan tetap atau memiliki penghasilan yang sangat kecil berdasarkan standar kemiskinan. Dari hasil penelitian, maka dapat disimpulkan bahwa, pelaksanaan program keluarga harapan sebagai produk kebijakan pemerintah dalam memutus mata rantai kemiskinan dalam pandangan etika utilitarinisme memberikan dampak. Dari sisi manfaat yang dapat diambil dari program keluarga harapan di Kota Palopo adalah menambah pemasukkan bagi kelompok penerima manfaat program yaitu efek terhadap pemasukan rutin peserta program keluarga harapan dalam sisi pendapatan dan pengeluaran rutin terutama untuk sektor pendidikan. Dari sisi manfaat dalam situasi yang lebih besar dalam pelaksanaan program ini adalah memberikan perubahan mindsett masyarakat prasejahtera untuk mau merubah satus dan kondisi menjadi masyarakat yang sejahtera dan; untuk manfaat yang besar bagi sebanyak mungkin orang adalah program ini mampu memberikan insurance effect kepada para kelompok penerima manfaat program untuk menjadi berdaya dan memiliki kemampuan untuk berubah kondisi.

Adapun saran-saran yang bisa dimunculkan pada penelitian ini adalah, dalam Pelaksanaan PKH perlu adanya alokasi dana yang sifatnya mampu membentuk usaha ekonomi kolektif secara berkelanjutan, sebab pada praktiknya alokasi anggaran kerap diperuntukkan bagi hal-hal yang tidak berkenaan dengan program tetapi masih dalam ranah pemenuhan kebutuhan sandang dan pangan, perlu adanya usaha dari pemerintah untuk menempatkan anak peserta PKH yang memiliki prestasi akademik ke institusi pendidikan yang memiliki kualitas lebih contohnya disekolah-sekolah unggulan, dan perlunya dibentuk pendidikan anak usia dini bagi kategori balita sebagai langkah awal pendidikan karakter seperti yang dicita-citakan oleh program ini. 


\section{MINISTRATE}

\section{Referensi}

Badan Pusat Statistik. (2016). Survei Sosial Ekonomi Nasional (Susenas) Tahun 2015. Jakarta: Badan Pusat Statistik.

Chandler, R.C., Plano, J.C. (1988). The Public Administration Dictionary. John Wiley \& Sons.

Cooper. L. T. (1998). The Responsible Administrator: an approach to ethics for the administrative role. United State : Jossey Bay.

Creswell. (2014). Research Design: Pendekatan Kualitatif, Kuantitatif dan Mixed.Yogyakarta: Pustaka Pelajar.

Donahue, J., Zeckhauser, R.J. (2011). Collaborative Governance: Provate Roles For Public Goals in turbulent times. New Jersey: Princenton University Press.

Dye, T.R. (2013). Understanding Public Policy. 14 ${ }^{\text {th }}$ Edition. New Jersey. Prentice Hall.

Frederickson H.G. (1997). The Spirit of Public Administration.San Francisco, California: JosseyBass Inc, Publisher.

Friedrich C. J. 1963. Man and His Government. Newyork: Mc Graw-Hill

Graham, G. (2015). Teori-Teori Etika. Cetakan I. Bandung. Nusa Media.

Haryatmoko, J. (2013). Etika Publik: Untuk Integritas Pejabat Publik dan Politisi. Jakarta. Gramedia Pustaka Utama.

Keban, Y. T. (2008). Enam Dimensi Strategis Administrasi Publik : Konsep, Teori, dan Isu. Yogyakarta. Gava Media

Kumorotomo, W. (2008). Etika Administrasi Negara. Jakarta: Raja Grafindo Persada.

Lever, A., Poama, A. (2019). The Routledge Handbook of Ethics and Public Policy. New York. Routledge.

Parsons, W. (2014). Public Policy: Pengantar Teori dan Praktik Analisis Kebijakan. Edisi Terjemahan. Cetakan ke 5. Jakarta. Fajar Interpratama Mandiri.

Patton, M. Q. (2009). Metode Evaluasi Kualitatif. Yogyakarta: Pustaka Pelajar.

Program Keluarga Harapan. 2020) Kementerian Sosial https://kemensos.go.id/programkeluarga-harapan-pkh [Accessed 8th Oktober 2020].

Program Keluarga Harapan. (2019): https://pkh.kemensos.go.id [Accessed 17th December 2020]

PKH, Kota Palopo. (2018). Rekap KPM-PKH Kota Palopo. Palopo. Tim Pendamping PKH Kota Palopo.

Shafritz, J.M., Russell, E.W. (1997). Introducing Public Administration. USA. Longman.

Wolf, J. (2020). Ethics and Public Policy: A Philosophical Inquiry. 2nd edition. New York. Routledge.

Winarno, B. (2012). Kebijakan Publik: Teori, Proses, dan Studi Kasus. Yogyakarta: CAPS. 